\title{
Detection of Five Differentially Expressed Proteins of Capsulation-resistant and Sensitive Osteosarcoma Tissues by Western Blot Technique in Vitro
}

\author{
Li-heng ZHANG ${ }^{a}$, Liang $\mathrm{LI}^{\mathrm{b}}$ \\ Jilin province people's hospital, Changchun, 130021

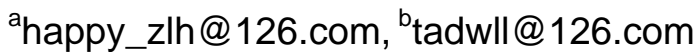

Keywords: Osteosarcoma, Western Blot, Differentially expressed proteins

\begin{abstract}
The tissue samples of cisplatin-resistant and sensitive patients with human osteosarcoma were obtained through chemosensitivity testing before. Five typical differentially expressed proteins of cisplatin-resistant and sensitive osteosarcoma tissue samples were analyzed by two-dimensional electrophoresis and the relevant differentially expressed proteins were obtained before. By Western Blot techinique in vitro, Two three-representative-tissues on cisplatin-resistant and sensitive osteosarcoma were chosen to test which is the differently expressed of 5 proteins. It is concluded that ALDOA and PGK1 may be the right markers in cisplatin chems in trating human osteosarcoma.
\end{abstract}

\section{Introduction}

The treatment of tumors resistant to cytotoxic drugs is not only an important reason for treatment failure, but also an important factor to limit the chemotherapy ${ }^{[1-4]}$. The mechanism is complex, it is determined by the character of tumor, such as the proportion of viable cells, the adequacy of the blood supply, the specific cellular mechanisms and MDR phenotype ${ }^{[2-4]}$. Among them, multi drug resistance (MDR) is one of the main obstacles in clinical cancer chemotherapy ${ }^{[5,6]}$. It is a particular phenomenon produced by tumor cells resistant. Its characteristics are that once the cells resistant to certain drugs generated, the drugs with other different structures and mechanisms of action produce cross-resistance phenomenon. In the past 10 years, many scholars dedicated to research of multidrug resistance in tumor ${ }^{[7-9]}$.

Cisplatin can abtain its effect of chemotherapy by inducting osteosarcoma cell autophagy activation ${ }^{[10-12]}$. Because of this, it is one of the three main drugs osteosarcoma neoadjuvant chemotherapy Rosen T Series program ${ }^{[13]}$. From the experiments completed for the first ${ }^{[14]}$ and second step ${ }^{[15]}$, it has been verified that cisplatin is a rational drug for ongoing study of multidrug resistance. Cisplatin-resistant and sensitive osteosarcoma tissue in the first step experiment is selected, and a typical one of cisplatin-resistant and sensitive osteosarcoma tissue samples were analyzed by two-dimensional electrophoresis and the relevant differentially expressed proteins were obtained. Five differentially expressed proteins were obtained through the analysis of mass spectrometry technology and identified comparing with protein databases. This experiment is the third step of the multi-drug resistance study.

\section{Experimental methods}

General Material. Choose two three-representative-tissue on cisplatin-resistant and sensitive osteosarcoma.

Reagents. Stock solution and working solution preparation.

\section{Tissue protein extraction}

1. Tissue blocks were weighed. 2. Using liquid nitrogen, pulverized tissue blocks in a mortar. 3 Add RIPA buffer (per gram of tissue $3 \mathrm{ml} \mathrm{RIPA),} \mathrm{PMSF} \mathrm{(per} \mathrm{gram} \mathrm{of} \mathrm{tissue} 30 \mu 1,10 \mathrm{mg} / \mathrm{ml}$ PMSF), further homogenized using Polytron $(15,000 \mathrm{rpm} / \mathrm{min} 1 \mathrm{~min})$ and maintained $4^{\circ} \mathrm{C} .4$ Add PMSF (per gram of tissue $30 \mu 1,10 \mathrm{mg} / \mathrm{ml}$ PMSF), incubated on ice for 30 minutes. 5. Iingraft into 
centrifuge tubes $4^{\circ} \mathrm{C}$ approximately $20,000 \mathrm{~g}(15,000 \mathrm{rpm})$ for 15 minutes. 6. Supernatant of cell lysates, divided into equipment stored at $-20{ }^{\circ} \mathrm{C}$. 7. Bradford colorimetric assay for protein concentration.

\section{SDS-polyacrylamide gel electrophoresis}

1 Installed shelves. 2 Separation gel prepared according to the following formula (Total: $8 \mathrm{ml}$ ) Adding a layer of distilled water in the gel above to promote better glue agglutination. 3 Preparation of concentrated gel after separating gel set. (Total: $3.5 \mathrm{ml}$ ) Insert a pre-prepared comb then. 4 After gelling be set, sample, electrophoresis. Upper gum set with $60-80 \mathrm{~V}$ voltage, when the sample to separation gel, set 100-120V. General electrophoresis was 1.5 hours.

Adding a layer of distilled water in the gel above to promote better glue agglutination.

\section{Electrotransfer (semidrying process)}

1 experiment condition selection.Currently $1 \mathrm{~mA}-2 \mathrm{~mA} / \mathrm{cm} 2$ was used. We usually use $100 \mathrm{~mA} /$ film, to choose transfer time according to the size of the protein molecule and gum concentration, and adjustments could be taken specifically based on the actual appropriate. 2 Experimental operation(1) The filter paper and membrane preparation (2) transfusion

Block Before the end of the transferation prepared 5\% Milk (TBST solution). Transferred into the milk in the film after the end of block (be sure to put a clean container to avoid contamination and should be sufficient to cover the film), tidy and clean filter paper used for the next use. Block $4{ }^{\circ} \mathrm{C} \mathrm{O} / \mathrm{N}$, or RT $1 \mathrm{hr}$.

No 1 antibody incubation The diluted antibody and membrane were incubated. Generally used RT $1 \mathrm{hr}$. According to the volume and membrane antigen antibody appropriate to extend or shorten the time. Ablution Quick first washed three times with TBST, wash out the milk as soon as possible. Then 5 mins $* 5$. Washing is to wash away the first antibody and antigen non-specific binding. The effect of washing directly affect the results of the background shades. No 2 antibody incubation RT incubation 1 hours. Generally used the HRP-conjugated secondary antibody. 1:5000 dilution.Ablution Quick first washed three times with TBST, wash out the milk as soon as possible. Then 5 mins for 5 times. Color (HRP enzyme) by enhanced chemiluminescence (ECL).

\section{Results}

2-D electrophoresisWe cisplatin-sensitive three osteosarcoma cells as well as three resistant cells described above five related proteins detected. The results show ALDOA and PGK1 kinases expression of the two groups was significant difference, while the other three proteins there was no significant difference. The results shown in Figure 1.

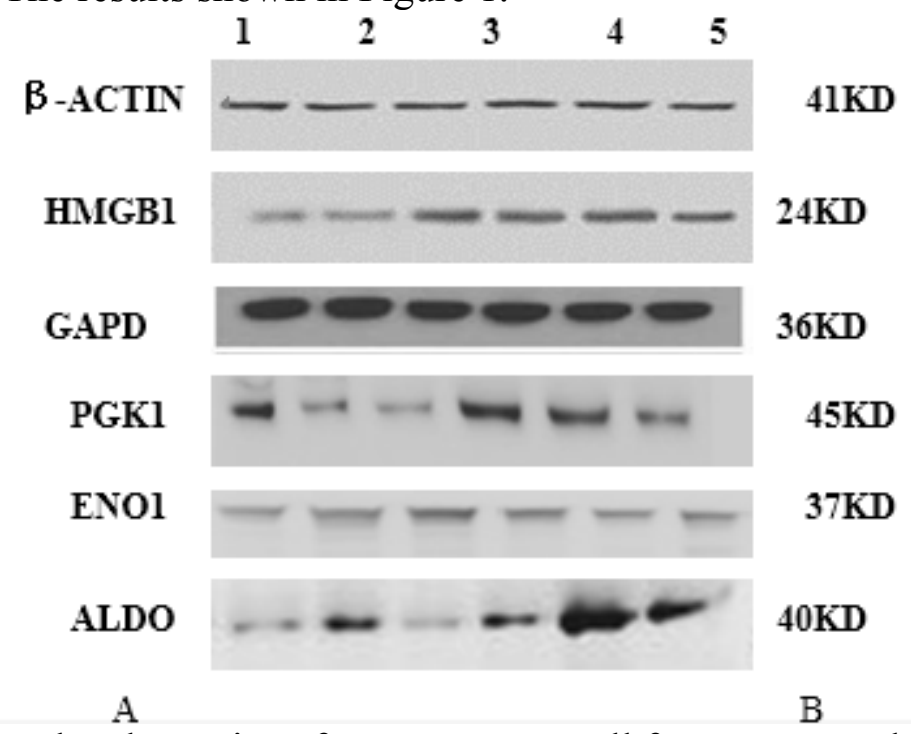

Fig.1 Five related proteins of osteosarcoma cell from wesstern blot results. 


\section{1,2,3: cisplatin-sensitive osteosarcoma cells; 4,5,6: cisplatin-resistant osteosarcoma cells.}

Table 1. Determination of protein expression results gray value (gray value detecting protein / protein $\beta$-ACTIN internal reference grayscale value) $* p<0.05, n=3$

\begin{tabular}{cccccc} 
& HMGB1 & ALDOA & PGK1 & ENO1 & GAPDH \\
\hline cisplatin-sensitive & & & & & \\
osteosarcoma cells & $0.91 \pm 0.02$ & $0.56 \pm 0.12$ & $0.78 \pm 0.26$ & $0.48 \pm 0.05$ & $2.56 \pm 0.23$ \\
cisplatin-resistant & & & & & \\
osteosarcoma cells & $1.02 \pm 0.023$ & $1.45 \pm 0.15^{*}$ & $1.36 \pm 0.37 *$ & $0.52 \pm 0.09$ & $2.79 \pm 0.33$ \\
\hline
\end{tabular}

\section{Conclusion}

Expression of ALDOA and PGK1 was significant different in cisplatin's treating human osteosarcoma with statistical significance. The two proteins may be the right marker in cisplatin chems in treating osteosarcoma.

\section{References}

[1] Li Liang, Zhou Y.,et al. Comparision of Two Blocking Solutions in The Treatment of the Lumer Facet Joint of OSteorathritis, Journal of Investigative Medicine, 61(4)S(2013), p.S11-S12.

[2] ZHANG Li-heng, LI Liang, LI Xiao-feng, et al. A experimental study on chemosensitivity to Osteosarcoma in vitro. Chinese Journal of Laboratory Diagnosis. 17(1)(2013), p.100-102.

[3] Li-heng ZHANG, Liang LI. Detection of Differentially Expressed Proteins of Capsulation-resistant and Sensitive Osteosarcoma Tissue. Advanced Materials Research. (2013), p.4553-4556.

[4] Dorfman H D, Czerniak B. Osteosarcoma. In: Dorfman HD, Czerniak B, eds. Bone tumors, 1st edn. St Louis, MO: Mosby. (1998), p.128-252.

[5] Takeshita H, Kusuzaki K, Ashihara T, et al. Intrinsic resistance to chemotherapeutic agents in murine osteosarcoma cells [J]. J Bone Joint Surg Am, 82-A(7) 2000, p.963-969.

[6] Duffaud F, Digue L, Mercier C, etc. Recurrences following primary osteosarcoma in adolescents and adults previously treated with chemotherapy. J. Eur J Cancer. 39 (2003), p.2050-2057.

[7] Tjalma RA. Canine bone sarcoma: estimation of relative risk as a function of body size. J. J Natl Cancer Inst. 36(1966), p.1137-1150.

[8] Bacci G, Longhi A, Fagioli F, et al. Adjuvant and neoadjuvant chemotherapy for osteosarcom of the extremities: 27 year experience at Rizzoli Institute, Italy [J]. Eur J Cancer. 41(18)(2005), p.2836-2845.

[9] Thorpe WP, Reilly JJ, Rosenberg SA. Prognostic significance of alkaline phosphatase measurements in patients with osteogenic sarcoma receiving chemotherapy. Cancer. 4(3)(1979), p.2178-2181.

[10] Ettinger LJ, Douglass HO Jr, Mindell ER, etc. Adjuvant Adriamycin and cisplatin in newly diagnosed, nonmetastatic osteosarcoma of the extremity.J. J Clin Oncol. 4(3) (1986), p.353-362.

[11] Bacci G, Briccoli A, etc. Neoadjuvant chemotherapy for osteosarcoma of the extremities with synchronous lung metastases: treatment with cisplatin, Adriamycin and high dose of methotrexate and ifosfamide. J. Oncol Rep. 7(2)(2000), p.339-346. 
[12] Cui Q, Li D, Liu C, etc. The significance of MGMT protein detection in evaluation of osteosarcoma necrosis rate after cisplatin chemotherapy. J. Bosn J Basic Med Sci. 11(2)(2011), 80-83.

[13] Xu Wanpeng, Feng Chuanhan. Orthopaedic Oncology. M. Beijing: People's Medical Publishing House. 2001: 105-107.

[14] Le Vu B, de Vathaire F, Shamsaldin A, et al. Radiation dose, chemotherapy and risk of osteosarcoma after solid tumours during childhood. J. Int J Cancer. 77(1998), p.370-377.

[15] Zini N, Scotloandi N, Nini G, et al .Multidrug-resistance( MDR) phenotype of human osteosarcoma cells evaluated by quantitative morphological and electron microscopy analysis[J]. Biol Cell, 84 (3)(1995), p.195-204. 